\title{
Effect of Rake Angle on Chip Control in CNC Lathe Machining of Low Carbon Steel
}

\author{
M. Uthaykumar, R. Prasanna, D. Simson, R.M. Sakthi Sadhasivam, M. Lenin and P. Sumalatha Devi
}

\begin{abstract}
This paper aims to ingenuity of the machining of low carbon steel in order to control chip length and reduce cycle time of the component, to improve surface finish by increasing Rake angle. This approach is used to reduce hazard to the operator. Surface roughness is measured by digital dial gauge. Heat generated during the turning operation is measured by using thermocouple. It gives clear perception about the rake angle. Parameter levels are adjusted according to insert grade to handbook and discussed about the efficient coolant flow condition.
\end{abstract}

This paper reviews various machining parameters which affect turning operation of low carbon steel. Such as insert geometry, coolant flow, heat dissipation, depth of cut, spindle speed, feed rate.

Keywords--- Chip Control, Machining, Low Carbon Steel, Rake Angle, Feed Rate.

\section{INTRODUCTION}

$\mathrm{M}$ ACHINING plays a vital role in manufacturing industry. It is a method to remove excessive material from workpiece in order to achieve required size and shape. Excessive material is removed as chip. Removal of chip also influences the surface roughness of workpiece. Material can also be classified as ductile and brittle material. While machining brittle material the absorption of crack capacity is less so the propagation of crack is easy and form discontinuous chip. In case of ductile material the crack absorption capacity is higher than the brittle material so the crack cannot propagate through chip so it form continuous chip[1-3]. Positive higher rake angle improve machinability by reducing the friction between sliding chip and tool[2] Since effective chip control is necessary for automatic production system because any failure in chip control can cause lowering the productivity and worsening the operation due to frequent stop due to removal of chip from chuck and tool and to reduce the hazards to the operator[1]. It also reduce the surface roughness[4]. Continuous chip which affect productivity of

M. Uthaykumar, Professor, Faculty of Mechanical Engineering, Kalasalingam University,India.E-mail:uthaykumar@gmail.com

R. Prasanna, Department of Manufacturing Engineering, Alagappa Chetiyar College of Engineering and Technology, Karaikudi, Tamilnadu, India.E-mail:prasannaravi.g@gmail.com

D. Simson, Department of Manufacturing Engineering, Alagappa Chetiyar College of Engineering and Technology, Karaikudi, Tamilnadu, India.E-mail:adsimson@gmail.com

R.M. Sakthi Sadhasivam, Department of Manufacturing Engineering, Alagappa Chetiyar College of Engineering and Technology, Karaikudi, Tamilnadu, India. E-mail:sakthi211193@gmail.com

M. Lenin, Department of Manufacturing Engineering, Alagappa Chetiyar College of Engineering and Technology, Karaikudi, Tamilnadu, India. E-mail:Leninmercy@gmail.com

P. Sumalatha Devi, Department of Manufacturing Engineering, Alagappa Chetiyar College of Engineering and Technology, Karaikudi, Tamilnadu, India.E-mail:palathaa@gmail.com

DOI:10.9756/BIJIEMS.7549 ductile material component [2]. Low carbon steel (scr420hb) are taken machined by using cermet insert with the help of CNC lathe. There are three major factors that affect chip control change cutting condition (feed, depth of cut, spindle speed), changing tool geometry (rake angle).

\section{MATERIAL COMPOSITION}

Material name-SCR420HB (low carbon steel)

Material Composition

\begin{tabular}{|l|l|}
\hline Element & Composition Percentage \\
\hline Carbon & $0.17-0.23 \%$ \\
\hline Silicon & $0.15-0.35 \%$ \\
\hline Magnesium & $0.55-0.9 \%$ \\
\hline Phosphorous & $0.20 \mathrm{maxi}$ \\
\hline Sulphur & $0.020 \%$ \\
\hline Chromium & $0.85-1.25 \%$ \\
\hline Nickel & $0.20 \mathrm{maxi}$ \\
\hline Copper & $0.30 \mathrm{maxi}$ \\
\hline Boron & $10-30 \mathrm{ppm}$ \\
\hline Niobium & $0.015-0.35 \%$ \\
\hline
\end{tabular}

\section{Methodology}

In order to attain maximum production CNC lathe machine is used. 30nosof Low carbon steel pinion samples are selected for each operation shown in fig 2.3 \& 2, 4 for absorbing chip length during machining. And collected the chip of each operation individually in that selecting the maximum chip length to control. The observed data is shown below. Steps which are shown below help to reduce the chip length.

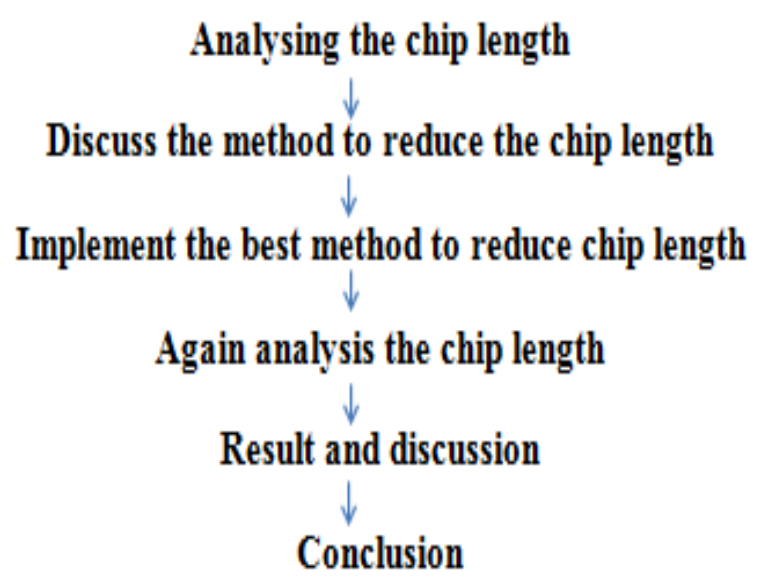




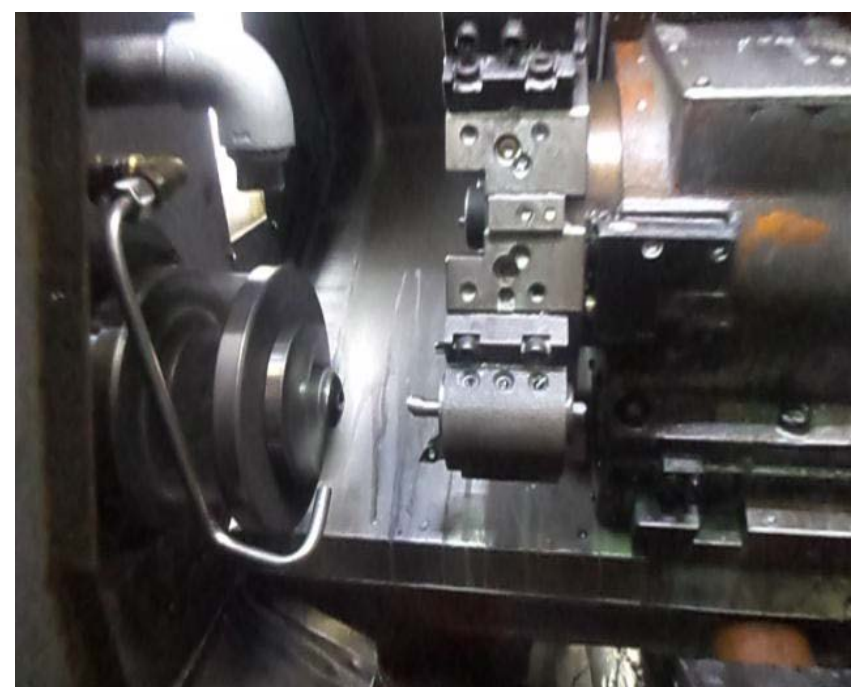

Fig. 2.1: Before Machining

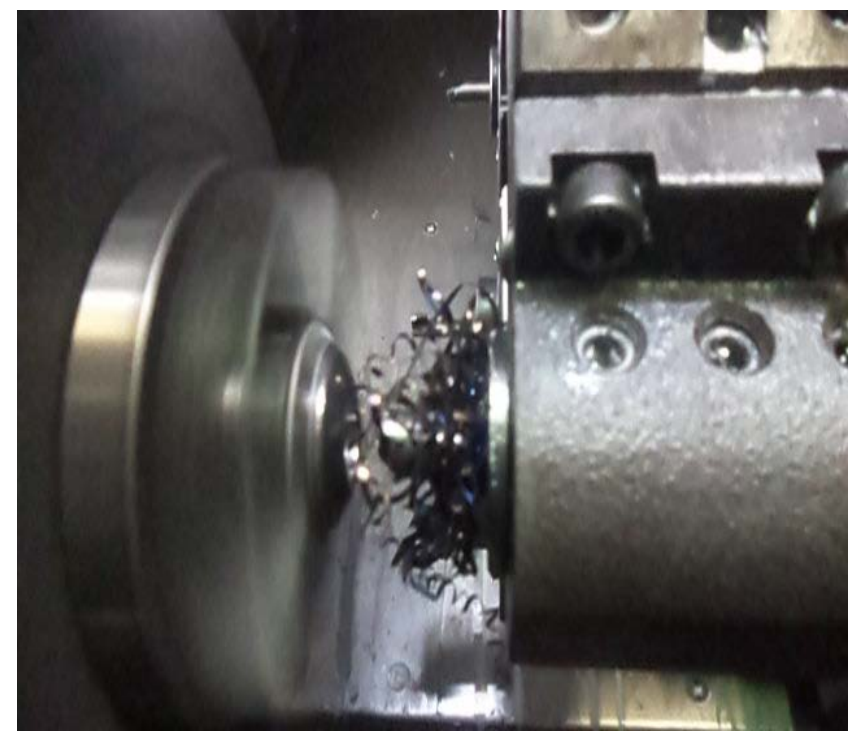

Fig. 2.2: After Machining Chips Curl on Tool

This is the pinion took for machining. And various turning operation had done for analysing chip control.

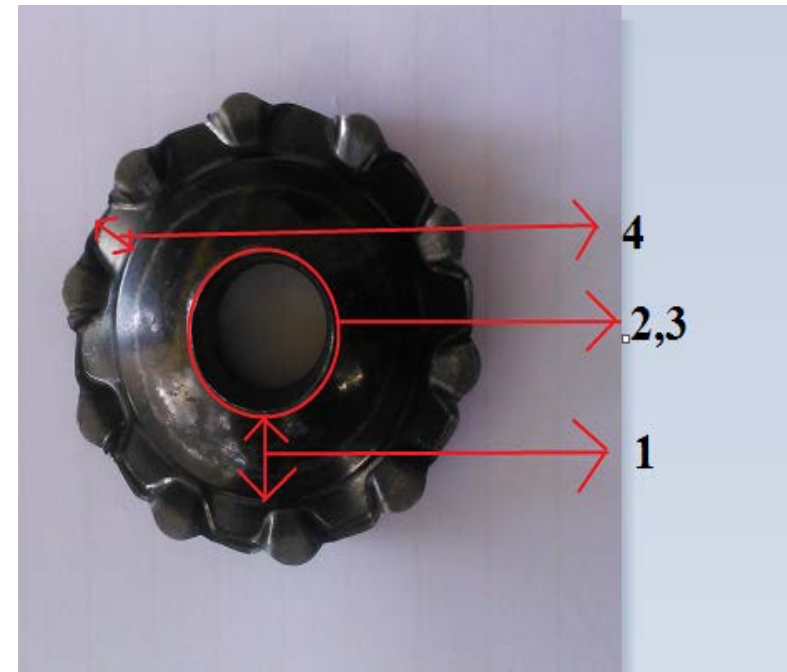

Fig. 2.3: Top View of Pinion

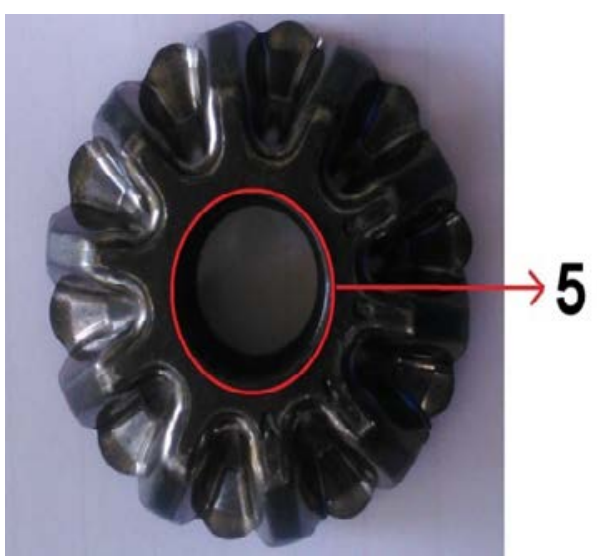

Fig. 2.4: Bottom View of Pinion

List of operation of pinion

1. Spherical finish

2. Bore rough

3. Bore finish

4. Back angle

5. Back radius

The machining parameters and chip length of a component while machining by existing insert is shown below in table 2.1.

Table 2.1: Machining Parameter and Chip Length for Existing Insert

\begin{tabular}{|l|l|l|l|l|l|}
\hline S.No & Operations & Stock Removal(mm) & Feed Rate(mmrev) & Spindle Speed(rpm) & Chip Length(mm) \\
\hline 1 & Backangle(Intermittent) & 3 & 0.12 & 3000 & 2 to 5 \\
\hline 2 & Backangle(Finish) & 3 & 0.12 & 3000 & 220 \\
\hline 3 & Spherical Finish & 0.5 & 0.1 & 2800 & 1200 \\
\hline 4 & Bore Rough & 1.7 & 0.25 & 2800 & 150 \\
\hline 5 & Bore Finish & 0.3 & 0.1 & 3000 & 1500 \\
\hline 6 & Back Radius & 0.5 & 0.1 & 2800 & 30 \\
\hline
\end{tabular}

From the observed data, the result of chip length is very high in spherical finish; bore rough, bore finish shown in table 2.2. Due to continuous chip it curl on tool and chuck there is a need of secondary equipment like blower to remove chip from tool and chuck, it increase cycle time and also increase cost per component. This paper focused mainly 3 operations to reduce the chip length. 
Table 2.2: Chips of Different Operation

Spherical finish

III. METHODOLOGY FOR CHIP CONTROL

- Insert geometry

- Heat dissipation

- Coolant flow

- Feed rate

- Depth of Cut

\subsection{Insert Geometry}

Insert geometry which is main factor for chip control. It is helpful to curl the chip properly. For that Rake angle should be positive and higher in insert geometry. Hence we choose insert TNMG130404 FS, CCMT 060208 MT, CCMT060204 FA for three operation spherical finish, bore rough, bore finish respectively [1]. There are so many insert with different material available in the market. As per the chemical composition of the work piece, carbide insert is selected.

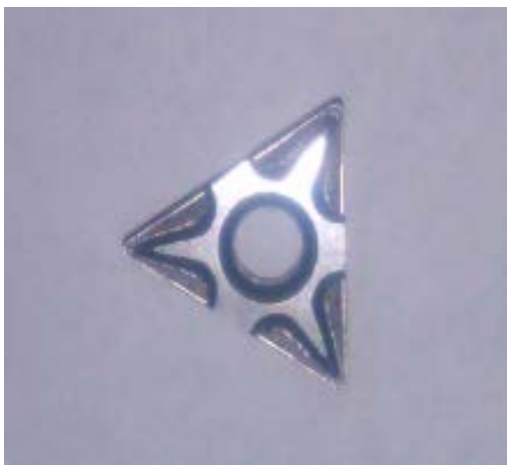

Fig. 3.1: Grooved Insert

\subsection{Heat Dissipation}

During machining of a component due to shearing of material by using cutting tool enormous amount of heat is generated. Mechanical energy is converted into heat (80\%) exactly on shear plane. $18 \%$ heat energy exactly on tool edge i.e. in between chip formation and tool. 2\% energy is converted into heat in between insert and work piece [1].

\subsection{Feed Rate}

The proper feed rate which help to curl the chip tightly. Feed should be greater than land width. Feed should be lesser than Groove width. If feed rate is lesser, the chip generation will escape from the groove. If feed rate is higher, the chip generation will touch the edge and escape from the groove [2].

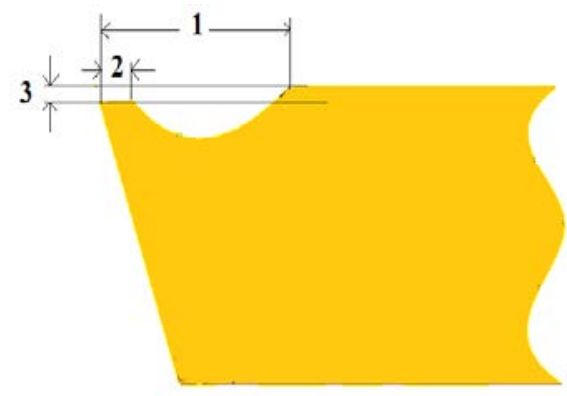

Fig. 3.2: 1-Grove Width, 2-Land Width, 3-Back Wall Height

For Example Groove width $=0.8 \mathrm{~mm}$. Feed rate $=0.2 \mathrm{~mm}$ to $0.8 \mathrm{~mm}$, Land length $=0.2 \mathrm{~mm}$.

\subsection{Coolant flow}

Coolant flow is used for quenching process. By using coolant tool life is increased [4-6]. It should be exactly on shear plane and deformation zone. Due to the continuous deformation of chip heat will generate at the curl chip. While the coolant flow is directly on the curl chip it makes more brittle. At the same time due to continuous bending of the chip so the crack in the chip will propagate and break into piece. It helps to change ductile material to brittle material. Coolant flow on deformation zone and shear plane helps to control chip and increases the tool life.

\subsection{Depth of cut}

As the general rule of thumb depth of cut should be greater than $60 \%$ of nose radius. 


\section{RESUlt AND DisCUSSION}

4.1. Spherical Finish
In case of spherical finish operation, existing insert changed to higher rake angle insert. And analysed chip length which are shown in table 4.1.

Table 4.1: Spherical Finish

\begin{tabular}{|l|l|l|l|}
\hline S.No & Parameter & Old Insert & New Insert \\
\hline 1 & INSERT & TNMG 130404 FM & TNMG 130404 FS \\
\hline 2 & GRADE & CT 3000 & CT 3000 \\
\hline 3 & BACK RAKE ANGLE & 5 & 10 \\
\hline 4 & SIDE RAKE ANGLE & 5 & 10 \\
\hline 5 & SPEED(N) & $2800 \mathrm{rpm}$ & $2800 \mathrm{rpm}$ \\
\hline 6 & DEPTH OF CUT (d) & $0.5 \mathrm{~mm}$ & $0.5 \mathrm{~mm}$ \\
\hline 7 & FEED(F) & $0.1 \mathrm{~mm} / \mathrm{rev}$ & $0.1 \mathrm{~mm} / \mathrm{rev}$ \\
\hline 8 & CHIP LENGTH & $1200 \mathrm{~mm}$ & $1-3 \mathrm{~mm}$ \\
\hline 9 & FIGURE & & \\
& & & \\
& & & \\
& & & \\
\end{tabular}

It is noted chip length is reduced from $1200 \mathrm{~mm}$ to $3 \mathrm{~mm}$ after the insert changed.

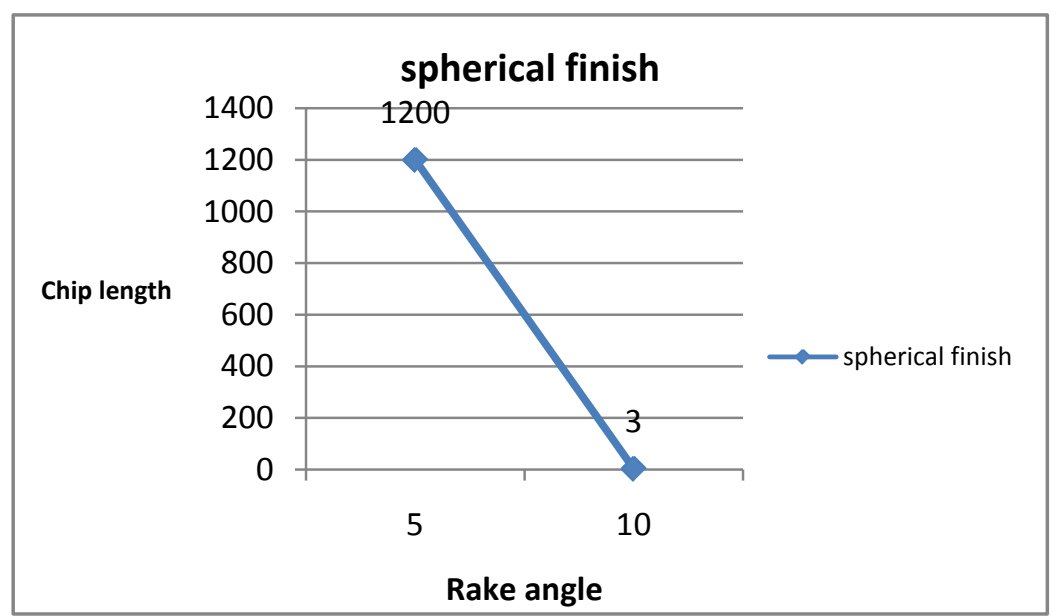

\subsection{Bore Rough}

In bore machining operation tool geometry and machining parameter as per the chip breaking methodology get changed. In case of bore rough operation, changing the insert geometry

having higher rake angle then the initial insert. And analysed chip length which are shown in table 4.2.

Table 4.2: Bore Rough

\begin{tabular}{|c|c|c|c|}
\hline $\begin{array}{l}S . \\
\text { No }\end{array}$ & Parameter & Old Insert & New Insert \\
\hline 1 & INSERT & CCMT 060208 N SU & CCMT 060208 MT \\
\hline 2 & GRADE & CCMP832ESU & CT 8115 \\
\hline 3 & $\begin{array}{l}\text { BACK RAKE } \\
\text { ANGLE }\end{array}$ & 0 & 4 \\
\hline 4 & $\begin{array}{l}\text { SIDE RAKE } \\
\text { ANGLE }\end{array}$ & 0 & 6 \\
\hline 5 & SPEED(N) & $2800 \mathrm{rpm}$ & $3500 \mathrm{rpm}$ \\
\hline 6 & DEPTH OF CUT (d) & $0.85 \mathrm{~mm}$ & $0.60 \mathrm{~mm}$ \\
\hline 7 & FEED(F) & $0.25 \mathrm{~mm} / \mathrm{rev}$ & $0.40 \mathrm{~mm} / \mathrm{rev}$ \\
\hline 8 & CHIP LENGTH & $150 \mathrm{~mm}$ & $15 \mathrm{~mm}$ \\
\hline 9 & FIGURE & & $\begin{array}{l}\text { when } \\
\text { Nhen }\end{array}$ \\
\hline
\end{tabular}


It is noted chip length is reduced from $150 \mathrm{~mm}$ to $15 \mathrm{~mm}$ after the insert changed.

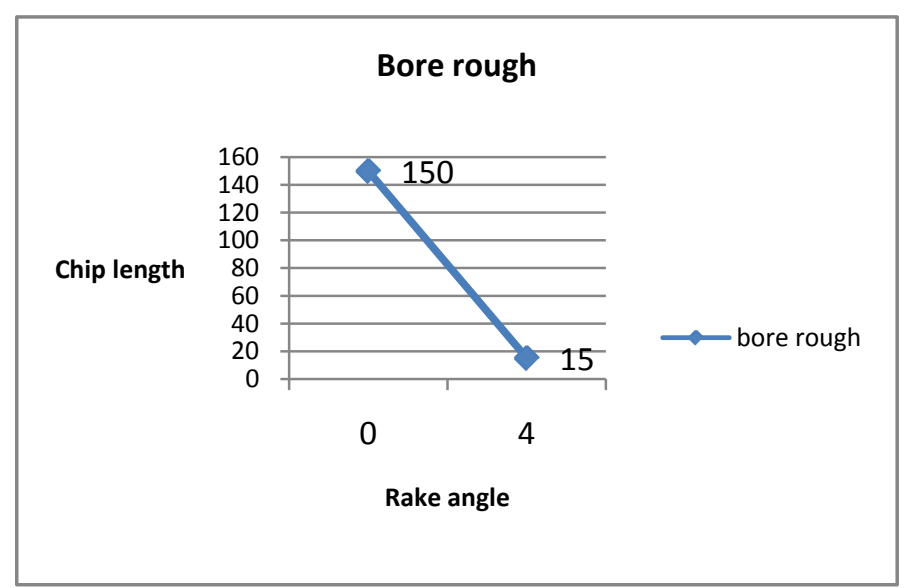

\subsection{Bore Finish}

In bore finish operation, insert geometry and machining operation are changed as per the chip breaking methodology. In case of bore finish operation, changing the insert geometry having higher rake angle then the initial insert. And analysed chip length which are shown in table 4.3

Table 4.3: Bore Finish

\begin{tabular}{|l|l|l|l|}
\hline S. No & Parameter & Old Insert & New Insert \\
\hline 1 & INSERT & CCMT 060204 FG & CCMT 060204 FA \\
\hline 2 & GRADE & CT 3000 & CT 3000 \\
\hline 3 & $\begin{array}{l}\text { BACK RAKE } \\
\text { ANGLE }\end{array}$ & 9 & 18 \\
\hline 4 & $\begin{array}{l}\text { SIDE RAKE } \\
\text { ANGLE }\end{array}$ & 17 & 18 \\
\hline 5 & SPEED(N) & $2800 \mathrm{rpm}$ & $3500 \mathrm{rpm}$ \\
\hline 6 & DEPTH OF CUT (d) & $0.25 \mathrm{~mm}$ & $0.40 \mathrm{~mm}$ \\
\hline 7 & FEED(F) & $0.09 \mathrm{~mm} / \mathrm{rev}$ & $0.09 \mathrm{~mm} / \mathrm{rev}$ \\
\hline 8 & CHIP LENGTH & $1500 \mathrm{~mm}$ & $37 \mathrm{~mm}$ \\
\hline 9 & FIGURE & & \\
& & & \\
& & & \\
\hline
\end{tabular}

It is noted chip length is reduced from $1500 \mathrm{~mm}$ to $37 \mathrm{~mm}$ after the insert changed.

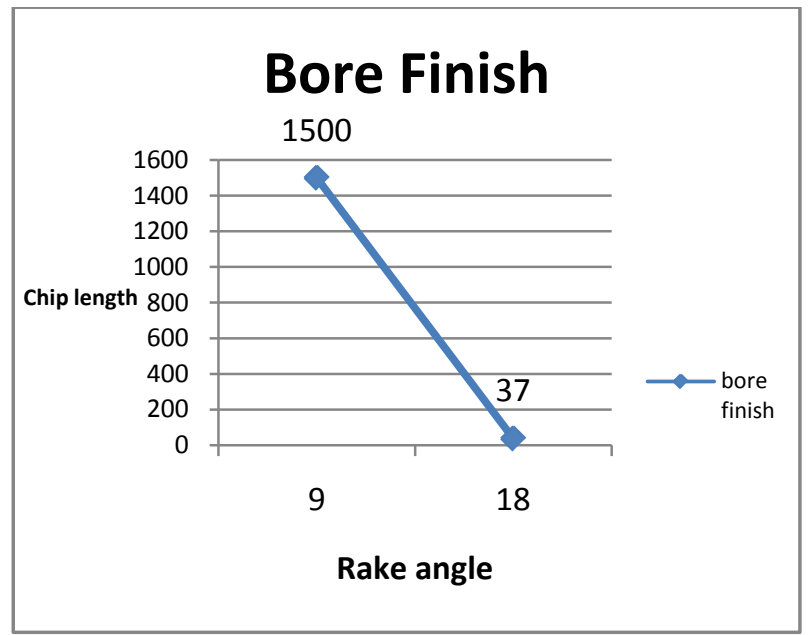

Table 4.4: Chip Length Before and After the Insert Change

\begin{tabular}{|l|c|c|}
\hline Operation & Existing chip length & Newchip length \\
\hline Spherical finish & & \\
\hline Bore rough & & \\
\hline Bore finish & & \\
\hline
\end{tabular}

\subsection{Inference}

By changing insert geometry and machining parameter as per the chip breaking methodology the chip length will be controlled. And that suggested insert, rake angle is greater than existing insert. Cost per component is 15\% increased. By reducing the chip length there is no curls of chip round the cutting tool. So it reduce the secondary equipment which used for removing curled chip. It can reduce 7 sec per parts by introducing the grooved insert.

\section{COST PER COMPONENT}

\subsection{Existing Cost per Component}

Table 5.1: Cost of a Component While Machining by Existing Insert

\begin{tabular}{|l|l|l|l|l|l|l|l|}
\hline Operation & Insert & $\begin{array}{l}\text { No .of Cutting Edge } \\
\text { (nos.) }\end{array}$ & $\begin{array}{l}\text { Life/ Edge } \\
\text { (nos.) }\end{array}$ & $\begin{array}{l}\text { Cost/ Insert } \\
{[\mathrm{A}](\mathrm{Rs})}\end{array}$ & $\begin{array}{l}\text { Life/ Insert } \\
{[\mathrm{B}](\mathrm{nos} .)}\end{array}$ & $\begin{array}{l}\text { Cost/ Component } \\
{[\mathrm{C}=\mathrm{A} / \mathrm{B}]}\end{array}$ & $\begin{array}{l}\text { Total Cost/ Part } \\
(\mathrm{Rs})\end{array}$ \\
\hline BACK ANGLE & CNMG 120408NM & 4 & 800 & 225 & 3200 & 0.07 \\
\hline SPHERICAL FINISH & TNMG 130404 FM & 6 & 450 & 195 & 2700 & 0.07 \\
\hline BORE ROUGH & CCMT 060208 N SU & 6 & 800 & 160 & 4800 & 0.03 \\
\hline BORE FINISH & CCMT 060204 FG & 2 & 250 & 160 & 500 & 0.32 \\
\hline BACK RADIUS & CCMT 060204 N SU & 2 & 350 & 160 & 700 & 0.22 \\
\hline
\end{tabular}


While machining by using less rake angle insert we spend nearly 0.71Rs for each component. As mentioned above table.

\subsection{New Cost Per Component}

Table 5.2: Cost of a Component While Machining by New Insert

\begin{tabular}{|l|l|l|l|l|l|l|l|}
\hline Operation & Insert & $\begin{array}{l}\text { No.of Cutting } \\
\text { Edge(nos.) }\end{array}$ & $\begin{array}{l}\text { Life/Edge } \\
(\text { nos. })\end{array}$ & $\begin{array}{l}\text { Cost/Insert } \\
{[A](\text { Rs })}\end{array}$ & $\begin{array}{l}\text { Life/Insert } \\
{[B](\text { nos. })}\end{array}$ & $\begin{array}{l}\text { Cost/ Component } \\
{[C=A / B]}\end{array}$ & $\begin{array}{l}\text { Total Cost/ } \\
\text { Part(Rs) }\end{array}$ \\
\hline BACK ANGLE & $\begin{array}{l}\text { CNMG } \\
\text { 120408NM }\end{array}$ & 4 & 800 & 225 & 3200 & 0.07 & 0.82 \\
\hline $\begin{array}{l}\text { SPHERICAL } \\
\text { FINISH }\end{array}$ & $\begin{array}{l}\text { TNMG 130404 } \\
\text { FS }\end{array}$ & 6 & 360 & 195 & 2160 & 0.09 \\
\hline BORE ROUGH & $\begin{array}{l}\text { CCMT 060208 } \\
\text { MT }\end{array}$ & 6 & 640 & 160 & 3840 & 0.04 \\
\hline BORE FINISH & $\begin{array}{l}\text { CCMT 060204 } \\
\text { FA }\end{array}$ & 2 & 200 & 160 & 400 & 0.40 \\
\hline BACK RADIUS & $\begin{array}{l}\text { CCMT 060204 } \\
\text { N SU }\end{array}$ & 2 & 350 & 160 & 700 & 0.22 \\
\hline
\end{tabular}

While machining by using higher rake angle insert we spend nearly 0.82Rs for each component. As mentioned above table.

\subsection{Cycle Time Reduction}

Table 5.3: Difference in Cycle Time of a Component before and after the Insert Change

\begin{tabular}{|c|c|c|c|c|}
\hline Operation & Existing Cycle Time/Part(sec) & Total Cycle Time/Part(sec) & New Cycle Time/Part(sec) & Total Cycle Time/Part(sec) \\
\hline Back Angle & 15 & \multirow{5}{*}{51} & 15 & \multirow{5}{*}{44} \\
\hline Spherical Finish & 07 & & 07 & \\
\hline Bore Rough & 09 & & 06 & \\
\hline Bore Finish & 15 & & 11 & \\
\hline Back Radius & 05 & & 05 & \\
\hline
\end{tabular}

\subsection{Cost Per Component Difference}

As per the standard CNC machining cost of 1 hour is 180 rupees

i.e., 3600 seconds $=$ Rs. 180

1 second $=$ Rs. 0.05

We can reduce 7 seconds per part by introducing new insert.

\section{7 seconds $=$ Rs. 0.35}

By using grooved insert which have high rake angle the cost per component in increased nearly 0.11 rupee per component. But the cycle time for a component is reduce from $51 \mathrm{sec}$ to $44 \mathrm{sec}$. It can save $7 \mathrm{sec}$ for one component. Now for a single component the total cost is 0.57 . And we get profit of 0.14 rupee per component.

\section{CONCLUSION}

Chip length is reduced by increasing the rake angle of the insert and it also reduce the cycle time of the component.

It proves that cost of a component is decreased just by increasing the rake angle of the insert.

Reduce cutting forces and power requirements.

Easy chip disposal.

Safety to the operator.

Avoid use of blower which helps to save electricity.

\section{REFERENCES}

[1] Kundan Kumar Singh, Mayankjoshi, Anurag Bahuguna and Rajesh Pant, "Effect of rake angles and material properties on chip formation: A Review”, International Journal of Engineering Science and Innovative Technology (IJESIT), Vol. 3, No. 6, Pp. 526-530, 2014.

[2] Tomoya Aoki, "Development of a high-performance chip guiding turning process-tool design and chip flow control”, Toyota Central R\&D Labs., Inc., Nagakute, Aichi, Japan.

[3] S. Buchkremer and J. Schoop, "A mechanics-based predictive model for chip breaking in metal machining and its validation", CIRP AnnalsManufacturing Technology, 2016.

[4] X. P. Zhang and S.B. Wu, "Chip control in the dry machining of hardened AISI 1045 steel”, The International Journal of Advanced Manufacturing Technology, Pp. 1-9, 2016.

[5] YK Chou, CJ Evans and MM Barash, "Experimental investigation on CBN turning of hardened AISI 52100 steel”, JMater Process Technology, Pp. 274-283, 2002

[6] S Chinchanikar and SK Choudhury, "Machining of hardened steelexperimental investigations, performance modeling and cooling techniques: a review”, Int J Mach Tools Manuf, Vol. 89, Pp. 95-109, 2015. 